\title{
Animal Experimentation and the Argument from Limited Resources
}

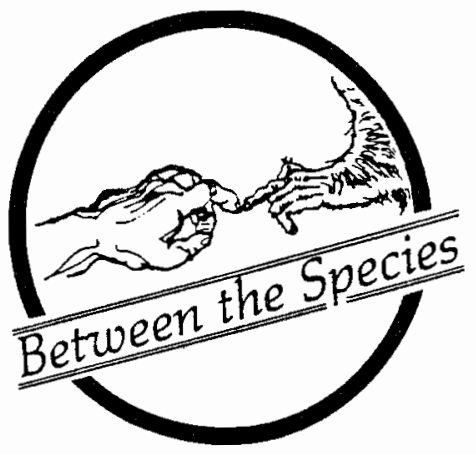

\author{
Charles K. Fink \\ University of Miami
}

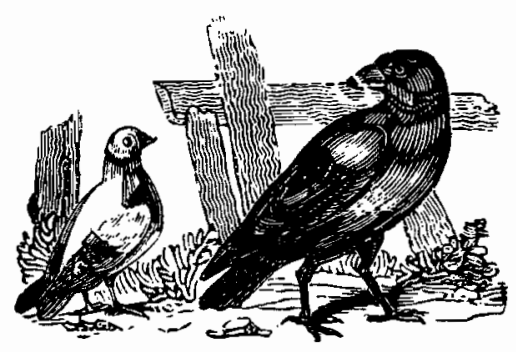

humane benefits that flow from it cannot outweigh the suffering of a rat" (214).

Some activists have questioned the sincerity of this humanitarian appeal. In his classic study on vivisection, Victims of Science, Richard Ryder observes:

Those with genuinely humane motives are most likely to prolong life or alleviate suffering by bringing existing medical knowledge to bear in those parts of the world where men and women are suffering and dying because they cannot afford any treatment. Yet many scientists prefer to spend their lives in laboratories causing untold suffering to animals in questionable medical research with a strong commercial motive; these researchers are not convincing when they plead that humanity is their over-riding concern (22).

Ryder's point is that health care professionals have a choice between applying their knowledge and skills in laboratory research or devoting themselves instead to providing basic medical care to the poor. The first choice involves inflicting untold suffering and death upon any number of animals in research which may never yield beneficial medical results. The second choice involves helping people directly without any harm coming to animals. It is this second choice, Ryder urges, that is the truly humane one. ${ }^{1}$

Gallistel's appeal to the humanity of the scientific enterprise is not uncommon among apologists for vivisection. The argument is that animal research is an indispensable tool in the treatment of disease and, consequently, to condemn such research, as activists do, is to condemn indefinitely many people to misery and death. One should accept restrictions on animal research, Gallistel insists, "only if one believes that the moral value of...scientific knowledge and of the many human and

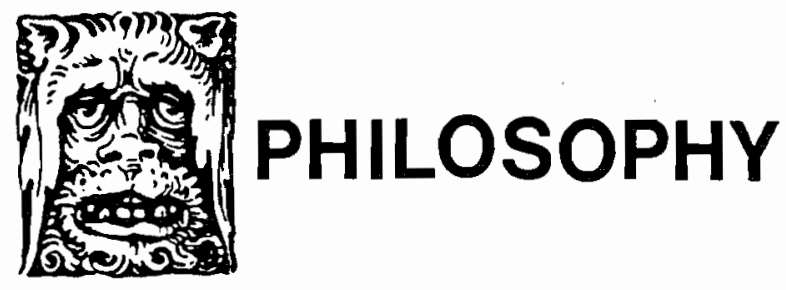


In a more recent study, Rosemary Rodd alludes to Ryder's argument:

No-one (I think) would attempt to argue that the lives of Third World children are less valuable than those of children in the developed countries, so there seems to be some merit in the argument of Richard Ryder that resources ought preferentially to be used to save human lives by means which do not involve contingent suffering for research animals. It certainly appears that there is no reason why an individual should not make a principled decision to support famine relief rather than, say, heart research (59).

The choice between supporting animal research or supporting other forms of humanitarian work is not one which only health care professionals must make, it is one faced by virtually all members of an affluent society. For example, the Muscular Dystrophy Association collects many millions of dollars each year from individual contributors. While not all of this money is used in animal research, a considerable portion of it is. Now, this charitable organization is only one among numerous others which compete with one another for our support. And while muscular dystrophy is a horrible and debilitating disease, so are many of the diseases, including chronic hunger, which afflict so many in the Third World. Further, diseases of poverty, unlike muscular dystrophy, are often preventable and curable. All things considered, therefore, would it not be better for contributors to support organizations-such as Food First, Grassroots International, and Co-op Americadevoted to improving the circumstances of people in the Third World than to support the Muscular Dystrophy Association?

This, I believe, amounts to a very powerful argument against animal experimentation, though it is only implicit in the writings mentioned above. The thrust of the argument is that whatever resources are currently being used to support animal research might alternatively be used for other humanitarian purposes, so that, all things considered, we might serve humanity as well or even better by altogether abandoning animal experimentation. Fully stated, the argument proceeds as follows: First:

Those individuals and organizations involved in animal research (whether directly as health care professionals or indirectly as supporters) might alternatively devote their energies and resources to other humanitarian causes.

Thus, physicians and health care organizations now engaged in animal research might instead devote their time and resources to providing medical care directly to those in need; and contributors to charitable organizations (which would include not only individuals, but private foundations and governmental agencies) might choose to donate whatever money they would otherwise contribute to animal research organizations to other public or charitable organizations. (For example, rather than contributing ten dollars to the Muscular Dystrophy Association, one might donate this money to a famine relief fund.) Second:

There is humanitarian work that is at least as beneficial to humanity as medical research, and moreover, does not involve harming laboratory animals.

For example, it is estimated that between 700 million and 1 billion people in the Third World are chronically malnourished. ${ }^{2}$ Over 2 billion do not have access to clean drinking water. ${ }^{3}$ Some 14,000 children go blind each year in India alone from insufficient protein. ${ }^{4}$ And worldwide between 18 and 20 million die from malnutrition and preventable diseases. ${ }^{5}$ Experts say that most of these deaths could be prevented by access to clean water, vaccines, oral hydration salts, and vitamins. ${ }^{6}$ In fact, over 60,000 children die each week from dehydration caused by diarrhea. ${ }^{7}$ Yet affluent nations continue to invest billions of dollars to research diseases that afflict comparatively few people. ${ }^{8}$ If the resources currently used to research diseases of affluence ${ }^{9}$ were instead devoted to providing food and basic medical care to the poor, the benefit to humanity would be far greater (and the cost to animals far less) than whatever benefits flow from animal research. Therefore:

Even if there are serious diseases that are treatable only by conducting animal research, we would still be justified in not conducting this research, but in devoting our limited resources to other forms of humanitarian aid.

In fact, the two premises seem to support an even stronger conclusion: 
Even if animal experimentation might eventually provide cures for many serious diseases, given the present state of the world, we are definitely not justified supporting this research; rather we ought to devote our limited resources to other forms of humanitarian assistance.

I shall refer to this argument; with either the stronger or the weaker conclusion, as the Argument from Limited Resources.

This argument, I believe, has an important place in the debate over animal experimentation. Much of this debate revolves around the following three points. First, most experiments on animals are performed not for valid scientific or medical reasons, but for commercial purposes. ${ }^{10}$ Second, because of well-known difficulties of extrapolating from one species to another, the results of animal experimentation are often unreliable. ${ }^{11}$ And third, in many cases, there exist alternatives to animal models in medical research, so that even when animal experimentation does yield important and reliable medical information, the use of animals may have been unnecessary. ${ }^{12}$ Still there remains a considerable amount of animal research (just how considerable it is is the subject of much controversy) which does provide important medical insights and, furthermore, cannot be replaced by other known research methods. One important strength of the Argument from Limited Resources is that it concedes this point, yet still provides a compelling reason to abandon animal experimentation. Even if cancer, for instance, might only be cured through extensive animal research, we would not be justified in conducting this research, because there are other even more serious social problems that have priority. Today some 14,000 Americans will die from cancer. ${ }^{13}$ In combating this disease, the National Cancer Institute will spend \$3 million, and the American Cancer Institute another \$1 million. ${ }^{14}$ Yet 40,000 children in the Third World will die from malnutrition and treatable diseases. ${ }^{15}$ According to World Vision, just 50 cents could feed a hungry child for two days. As Rosemary Rodd points out, no one can reasonably argue that the interests of Americans count for more than those of children in developing nations. Yet this is precisely the implication of a social policy that favors the welfare of American cancer patients over that of malnourished children in the Third World.
Another important feature of the Argument from Limited Resources is that it does not take a controversial stand concerning the moral status of nonhumans. Richard Ryder, Peter Singer, Tom Regan, and many others have argued against animal experimentation on the basis of the moral considerability of animals. Since animals have moral rights or are otherwise deserving of moral consideration, and since animal experimentation fails to show animals the moral respect they deserve, it follows that such experiments are immoral. While I believe that this argument, fully developed, is sound, defenders of animal experimentation have been very critical of the view that nonhuman animals are morally comparable to human beings. If animals are not, this would undermine the moral arguments of many philosophers, but it would not vitiate the Argument from Limited Resources. The point of this argument is not that animal research is wrong because of how it affects animals, but that it is wrong because of how it affects human beings. By investing whatever funds would otherwise be used in, say, cancer research in famine relief, the benefit to the human community would be far greater.

Finally, the Argument from Limited Resources provides a response to the complaint, noted earlier, that animal rights activists show more compassion for animals than for human beings. For now it can be argued that it is the activist and not the vivisectionist who shows true compassion for humanity. Every day millions of dollars are spent in animal research which provides no alleviation of human suffering, and may never do so. According to the animal rights activist, this money, if properly spent, could do far more for mankind than animal research has ever done.

This summarizes the important strengths of the Argument from Limited Resources. Let us now consider some possible objections to the argument.

One objection which might be raised is that the moral reasoning involved in the argument cannot be generalized without unacceptable consequences. If it is true, the objection goes, that we should not spend money on cancer research so long as there are starving children in the world, then it must also be true that we should not spend money on space exploration, transportation systems, industrial development, or the Strategic Defense Initiative, since the money expended on these endeavors could also be used to assist the poor. Yet these consequences are surely unacceptable. While there is, perhaps, much more that could be done to help 
the poor, doing so need not preclude other important and worthwhile endeavors; it need not, in particular, preclude animal research.

I agree with this objection up to a point. It is true that animal research is only one among many other immensely costly endeavors, and that there is no special reason why animal research, in consideration only of its neglect for humanity, should be singled out for criticism. While I concede this point, I think the proper conclusion to draw is not that animal research is excusable because space exploration is, but that neither one is excusable. In a much better world than our own, no one would seriously consider spending millions of dollars on space exploration when thousands of children die each day from starvation; and no one would consider spending millions on animal research when every day thousands of people die from treatable diseases.

Still, it may be argued, by redirecting funds from other sources it might very well be possible to combat poverty without abandoning animal research. If there is, in other words, no special reason why animal research should be singled out for condemnation, then there is no special reason why animal research rather than certain other costly practices should be abolished. If not all have to be abolished, then no one in particular does.

But this objection completely misses the point. It may well be true that not all people in affluent nations need to make sacrifices to improve the standard of living of people in developing nations, but this would hardly excuse any particular person from making no effort to improve things. Similarly, it may be true that by redirecting other resources significant improvements could be made in the health care of the poor without abandoning animal experimentation. But this does not excuse health care professionals for engaging in animal research rather than bringing their knowledge and skills to those people who need them most; nor does it undermine the point that contributors to charitable organizations (as well as all taxpayers) should think twice about donating their money to those organizations involved in animal research, and choose instead to donate their money to other worthy organizations. Since the objection does not undermine these two points, it does not vitiate the Argument from Limited Resources (certainly not the weaker version of this argument).

Another objection which might be raised is that the Argument from Limited Resources involves a certain inconsistency. The inconsistency consists in arguing that animal research should be abolished and our resources devoted to providing, among other things, basic medical care when, in fact, what we now recognize as basic medical care was made possible largely through the use of animal experimentation. The antivivisectionist, so it seems, wants to have the benefits of animal research without paying the price.

This objection has great metorical force, but little more. One response is to challenge the alleged importance of animal experimentation in the advancement of medical science. This is a highly controversial subject, but some critics of the medical establishment maintain that animal research, far from contributing significantly to the growth of medical knowledge, has actually hindered the advancement of medicine. ${ }^{16}$

Another possible response is to indicate that there are many forms of humanitarian assistance other than medical care. Each year many millions of people die from starvation or from diseases caused by various factors - such as inadequate sanitation-endemic to poverty. Even if these people received no direct medical care, it would still be possible to save millions of lives by supplying them with food and other forms of aid. (It has been argued, for instance, that the decline in mortality rates associated with infectious diseases is due less to medical discoveries based on animal research than it is to improved hygiene and sanitation. ${ }^{17}$ ) $\mathrm{A}$ proponent of the Argument from Limited Resources need not maintain that medical care should be provided to the poor but only that there are other forms of humanitarian work of greater potential value to mankind than animal research.

Yet, having said this, why shouldn't antivivisectionists accept the use of medical technology developed through animal research provided that this would not encourage further animal research? If this technology already exists, and if it would be possible to save lives or otherwise improve human health by making use of it, then, other things, being equal, we should. The position of anti-vivisectionists, as I understand it, is that we should not continue the practice of animal experimentation (which is not to suggest that we ever were justified in this practice), and that we should not make use of whatever products or drugs have been tested on animals because doing so only encourages further animal testing and supports those institutions that conduct it. It is not, or need not be, the position of anti-vivisectionists that even if animal experimentation is abolished, we should still not make use of any products or drugs that were developed through animal research. 
Another possible objection to the Argument from Limited Resources is that while it may be true that most animal experiments do not yield valuable medical results, some experiments certainly do. For example, it has been estimated that as many as 130 million lives have been saved by the discovery of insulin for the treatment of diabetes. The research upon which this discovery was based was made in 1921 by Frederick Banting and Charles Best working with several dogs who had been surgically rendered diabetic. ${ }^{18}$ Now, whatever objection there might be to this research, it cannot reasonably be argued that Banting and Best might have made a more significant contribution to humanity by devoting themselves to some other form of humanitarian service, such as providing basic medical care to the poor. Therefore, even if the Argument from Limited Resources does apply in some cases, it does not apply in all. ${ }^{19}$

I am willing to concede this point, but I do not believe is is a very forceful one. The objection admittedly applies only in those cases in which the resources (human or monetary) invested in animal research could not have been put to some more beneficial use. These cases may well be rare. But even if they are not, there is still some merit to the argument I advance. First of all, scientific research rarely proceeds in a vacuum. The work of one research team builds upon and complements the work of others, so that when success is achieved this is largely the result of a collaborative effort. Because of this, it is difficult to isolate individual experiments and defend them along the lines considered here. The true cost of success is often much greater than it appears. (There certainly were, for example, many scientists other than Banting and Best researching diabetes prior to the discovery of insulin.) Second, when animal experiments truly are medically necessary (that is, necessary in order to achieve certain medical results) it is never known beforehand what the results might be; otherwise these experiments were not truly necessary. C. R. Gallistel, in defending unrestricted animal research, argues that "There is no way of discriminating in advance the wasteof-time experiments from the illuminating ones with anything approaching certainty" (211). If this is true, then one can never know beforehand whether some animal research project will truly benefit mankind. This, coupled with the fact that one can know beforehand what the results of various forms of humanitarian aid will be (not to mention the certainty of the suffering and deaths of laboratory animals) seems to undermine the argument that animal research is justified because of the important medical results it sometimes yields.

Both points suggest that animal experimentation cannot be considered piecemeal, but only as a whole institution. Individual research projects may prove to be of immense importance to mankind. But because of the difficulty of isolating individual projects and predicting their results, we must ask whether the institution as a whole is morally defensible. The thrust of the Argument from Limited Resources is that the many billions of dollars invested each year in the animal research establishment might be put to better humanitarian use.

These, I believe, are the main objections to the Argument from Limited Resources. Throughout I have defended the argument on humanitarian or even humanist ${ }^{20}$ grounds. If my defense is satisfactory, then even those with no sympathy whatever for animals should still be critical of animal experimentation. For, as I have argued, to support this institution is to support a social policy which neglects the vital interests of the vast majority of humankind.

There remains one final point to consider. And this is that my argument has social application only so long as there exist more serious social problems than those which might be solved through animal research. I acknowledge this limitation, but sadly it is one that need not concern us for the foreseeable future.

\section{Notes}

${ }^{1}$ In a similar vein, Peter Singer remarks: "Those who are genuinely concerned about improving health care would probably make a more effective contribution to human health if they left the laboratories and saw to it that our existing stock of medical knowledge reached those who need it most" (92).

${ }^{2}$ See World Hunger: 2 and Roots of Failure: 195.

${ }^{3}$ Roots of Failure: 195.

${ }^{4}$ Applying Ethics: 324.

5 World Hunger: 3.

${ }^{6}$ Christian Science Monitor, 20 September 1990: 10.

7 "The Cost of AIDS," New Scientist, 17 March 1988: 22 (as reported in Animal Liberation: 92).

${ }^{8}$ Furthermore, many of these diseases are preventable. For example, studies indicate that a vegetarian diet can prevent $97 \%$ of all coronary occlusions, and up to $80 \%$ of all cancers may be due to diet and tobacco products. (Information from 
Diet for a New America: 247, and from a pamphlet provided by Physicians Committee for Responsible Medicine.) The position of animal rights activists is that the medical establishment could be far more effective in improving the health of the general population by concentrating upon the prevention rather than the treatment of disease. If it is true, for instance, that $80 \%$ of all caricers are caused by environmental factors, then the control of these factors would be far more effective in the war on cancer than any "magic bullet" developed through extensive animal research might possibly be.

${ }^{9}$ These are diseases-such as cancer, heart disease, osteoporosis, and diabetes-that are endemic to affluent societies. For more information on this topic, see Robbins' Diet for a New America.

${ }^{10}$ Ryder, for instance, reported back in 1975 that only one-third of the British research on animals fell into categories recognized as "medically necessary" (36).

${ }^{11}$ One notorious example is the thalidomide tragedy. Thalidomide was a drug widely used by pregnant women resulting in thousands of birth defects. Yet this drug was thoroughly tested on animals and thought to be perfectly safe. See Victims of Science: $42-43$ and Animal Liberation: $50-51$.

${ }^{12}$ Critics of animal experimentation have argued that computer models, insentient organisms, tissue cultures, and human subjects, among other alternatives, may replace the use of animals in some medical research. For a complete discussion, see Gendin's "The Use of Animals in Science."

${ }^{13}$ Diet for a New America: 251.

${ }^{14}$ Diet for a New America: 248.

${ }^{15}$ Christian Science Monitor: 10.

${ }^{16}$ See Sharpe's The Cruel Deception.

${ }^{17}$ Fuchs makes this argument in Who Shall Live? (as noted by Nelson in "Animal Models in 'Exemplary' Medical Research").

${ }^{18} \mathrm{My}$ discussion of the discovery of insulin is based upon Nelson's account in “Animal Models in 'Exemplary' Medical Research."

${ }^{19}$ The American Anti-Vivisection Society has produced a pamphlet, written by Brandon Reines, which is very critical of the actual role of animal experimentation in the discovery of insulin.

${ }^{20}$ The humanist, as I understand it here, is someone who maintains that only human beings are morally considerable.

\section{References}

Fuchs, Victor. Who Shall Live? (New York: Basic Books, 1975).

Gallistel, C.R. "The Case for Unrestricted Research Using Animals." Animal Rights and Human Obligations: 209-215.

Gendin, Sidney. "The Use of Animals in Science." Animal Rights and Human Obligations: 197-208.

Gurtov, Melvin and Maghroori, Ray. Roots of Failure (Connecticut: Greenwood Press, 1984).

Lappe, Frances Moore and Collins, John. World Hunger (New York: Grove Press, 1986).

Nelson, James Lindemann. "Animal Models in 'Exemplary' Medical Research." Between the Species 5 (1989) 195-204.

Olen, Jeffery and Barry, Vincent (eds.). Applying Ethics (California: Wadsworth, 1989).

Regan, Tom. The Case for Animal Rights (California: University of Califomia Press, 1983).

Regan, Tom and Singer, Peter (eds.). Animal Rights and Human Obligations (New Jersey: Prentice Hall, 1989).

Robbins, John. Diet for a New America (New Hampshire: Stillpoint, 1987).

Rodd, Rosemary. "Pacifism and Absolute Rights for Animals: a comparison of difficulties." Journal of Applied Philosophy 2 (1985): 53-61.

Ryder, Richard. Victims of Science (London: Davis-Poynter, 1975).

Sharpe, Robert. The Cruel Deception (Wellingborough, Northants: Thorsons, 1988).

Singer, Peter. Animal Liberation (New York: The New York Review of Books, 1990).

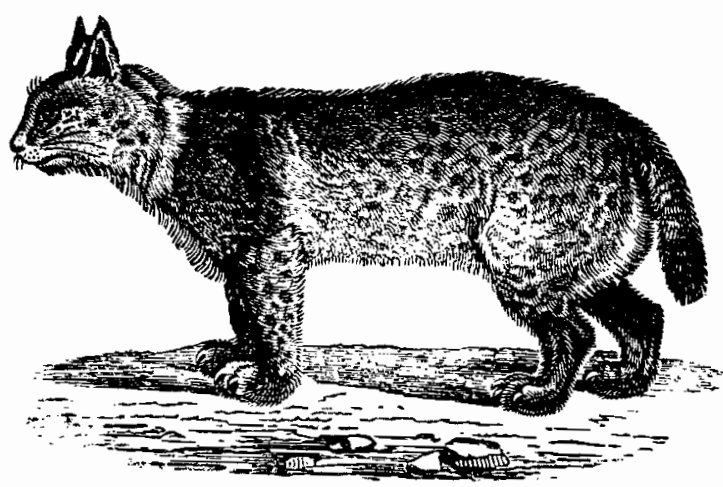




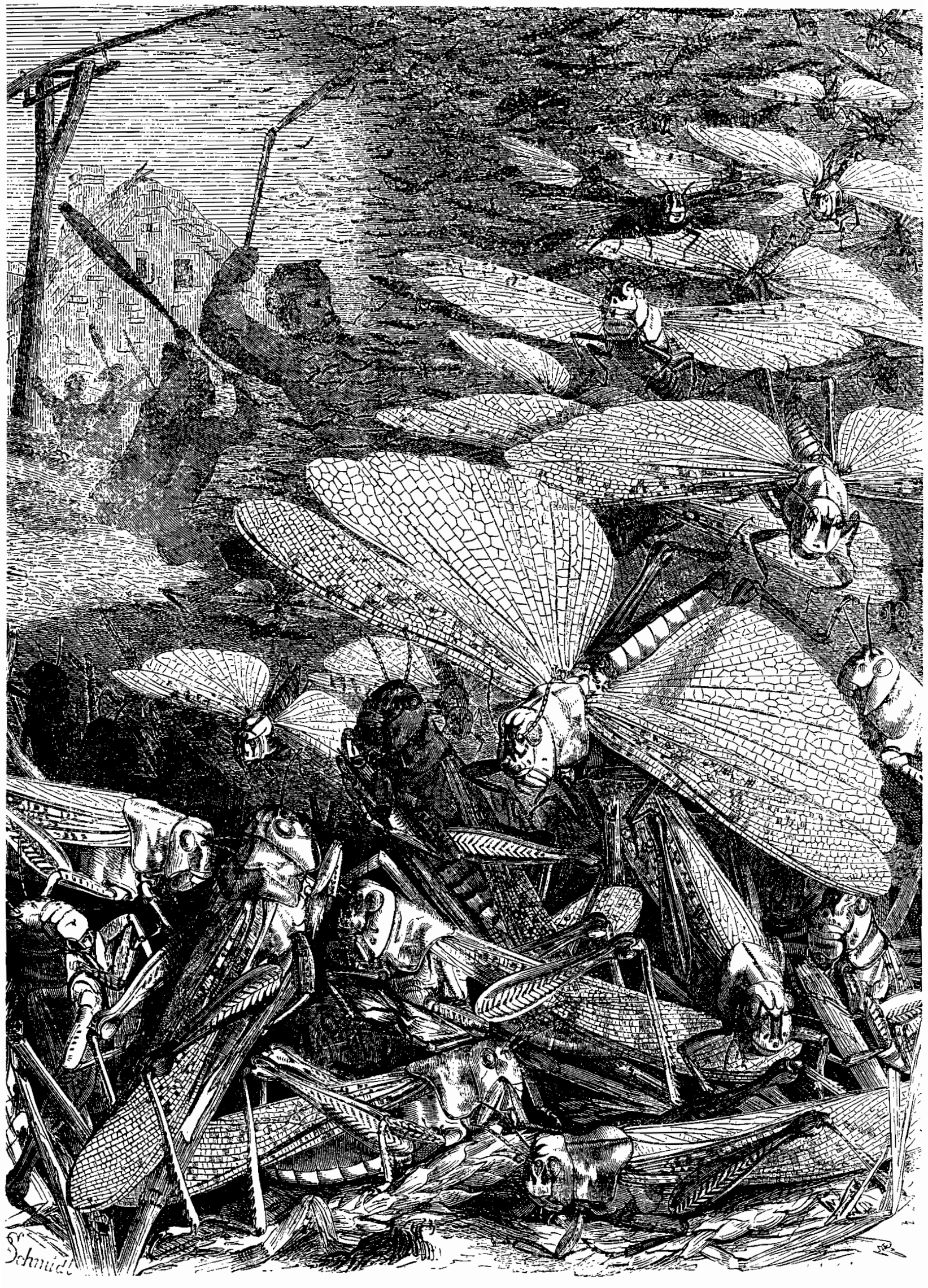

